\title{
The response of the South Asian Summer Monsoon circulation to intensified irrigation in global climate model simulations
}

\author{
Sonali P. Shukla • Michael J. Puma • \\ Benjamin I. Cook
}

Received: 31 July 2012/Accepted: 22 April 2013/Published online: 5 May 2013

(C) Springer-Verlag Berlin Heidelberg 2013

\begin{abstract}
Agricultural intensification in South Asia has resulted in the expansion and intensification of surface irrigation over the twentieth century. The resulting changes to the surface energy balance could affect the temperature contrasts between the South Asian land surface and the equatorial Indian Ocean, potentially altering the South Asian Summer Monsoon (SASM) circulation. Prior studies have noted apparent declines in the monsoon intensity over the twentieth century and have focused on how altered surface energy balances impact the SASM rainfall distribution. Here, we use the coupled Goddard Institute for Space Studies ModelE-R general circulation model to investigate the impact of intensifying irrigation on the large-scale SASM circulation over the twentieth century, including how the effect of irrigation compares to the impact of increasing greenhouse gas (GHG) forcing. We force our simulations with time-varying, historical estimates of irrigation, both alone and with twentieth century GHGs and other forcings. In the irrigation only experiment, irrigation rates correlate strongly with lower and upper level temperature contrasts between the Indian sub-continent and the Indian Ocean (Pearson's $r=-0.66$ and $r=-0.46$, respectively), important quantities that control
\end{abstract}

S. P. Shukla (凹) · B. I. Cook

NASA Goddard Institute for Space Studies, 2880 Broadway, New York, NY, USA

e-mail: sonali.p.shukla@nasa.gov

M. J. Puma

Center for Climate Systems Research, Columbia University, 2880 Broadway, New York, NY, USA

B. I. Cook

Lamont-Doherty Earth Observatory, 61 Route 9W, Palisades, NY, USA the strength of the SASM circulation. When GHG forcing is included, these correlations strengthen: $r=-0.72$ and $r=-0.47$ for lower and upper level temperature contrasts, respectively. Under irrigated conditions, the mean SASM intensity in the model decreases only slightly and insignificantly. However, in the simulation with irrigation and GHG forcing, inter-annual variability of the SASM circulation decreases by $\sim 40 \%$, consistent with trends in the reanalysis products. This suggests that the inclusion of irrigation may be necessary to accurately simulate the historical trends and variability of the SASM system over the last 50 years. These findings suggest that intensifying irrigation, in concert with increased GHG forcing, is capable of reducing the variability of the simulated SASM circulation and altering the regional moisture transport by limiting the surface warming and reducing land-sea temperature gradients.

Keywords South Asian Summer Monsoon · Irrigation · Latent heating $\cdot$ Monsoon intensity

\section{Introduction: intensifying irrigation and the South Asian Summer Monsoon}

Beginning in the 1960s, South Asia was witness to the Green Revolution: a period of unprecedented enhancement in agricultural production (Krishna Kumar et al. 2004) that helped avert potential regional famine conditions (Hazel 2009). Expansion and intensification of irrigation was a significant part of this effort: $40 \%$ of India's agricultural production comes from irrigated crops and 80-90\% of all water withdrawals in India are for irrigation purposes (Douglas et al. 2006; Mall et al. 2006a, b; Lal 2011). A significant amount is withdrawn from groundwater 
resources and introduced into the land-atmosphere domain, depleting these sources in many parts of India by up to $20 \mathrm{~cm} /$ year (Douglas et al. 2009). Adding large amounts of irrigation water can alter the surface energy balance between latent and sensible heating, which then impacts surface temperature, atmospheric water vapor, regional circulation patterns and rainfall (Douglas et al. 2006, 2009; Saeed et al. 2009; Niyogi et al. 2010). In fact, the resultant cooling from irrigation could mask surface warming that may otherwise be attributed to increasing greenhouse gas (GHG, see Table 1 for a list of all acronyms used herein and their expanded forms) emissions (Bonfils and Lobell 2007; Kueppers et al. 2007; Lobell et al. 2008).

This is of particular concern for the South Asian Summer Monsoon (SASM), which is dependent on the differential heating between the land surface and the sea to establish its circulation in the late spring/early summer (Wang 2006). Furthermore, the most heavily irrigated areas are located in northern India, a particularly dry region that is subject to large temperature increases prior to the Monsoon Season (Niyogi et al. 2010). The pre-monsoon heating of this region is critical to help establish the pressure gradients that drive the initial monsoon circulation (Webster and Yang 1992; Wang 2006 and references therein). Has the intensification of irrigation in this region altered the SASM circulation?

Some studies do suggest that the SASM intensity has weakened over 1960-2001 interval, perhaps due to reduction in the upper-level and lower-level land-sea temperature contrasts (Sun et al. 2010). This time period experiences both increasing irrigation and GHG forcing. GHG forcing has also contributed to rising equatorial Indian Ocean sea surface temperatures (SSTs), which have warmed by $0.5^{\circ}-1{ }^{\circ} \mathrm{C}$ compared to the early twentieth century (Alory and Meyers 2009). It is critical to understand the impact of each respective forcing (i.e., irrigation and GHG levels) on the monsoonal circulation.

As the southwesterly monsoon winds converge moisture onto the Indian sub-continent, Monsoon Season rainfall is often used to assess changes in the SASM. Empirical and

Table 1 Acronyms used and their expanded forms

\begin{tabular}{ll}
\hline Acronym & Expanded form \\
\hline GHG & Greenhouse gas \\
SASM & South Asian Summer Monsoon \\
GCM & General circulation model \\
MI & Monsoon intensity \\
CDC & NCEP climate diagnostics center derived analysis \\
CV & Coefficient of variation \\
LHF & Latent heat flux \\
ABCs & Atmospheric brown clouds \\
\hline
\end{tabular}

regional-model studies of the Indian-subcontinent have shown that intensive irrigation is more impactful to monsoonal rainfall totals and distribution than the change from natural vegetation to agricultural landscapes (Douglas et al. 2006, 2009; Lee et al. 2008; Niyogi et al. 2010). Increased latent heating over heavily irrigated regions alters the convective available potential energy and surface temperature, which may affect the SASM land-sea temperature contrasts (Douglas et al. 2006, 2009; Lee et al. 2008; Saeed et al. 2009). Changes in the surface energy balance were also a consistent finding among general circulation model (GCM) experiments (Puma and Cook 2010; Cook et al. 2011; Guimberteau et al. 2011). This had the effect of delaying the SASM onset and weakening the Monsoon Season rainfall, which is consistent with regional model findings (Guimberteau et al. 2011) and highlights the potential impact of irrigation intensity to initial monsoon development. GCM simulations showed that as GHG forcing increased, an irrigation-induced cooling over South Asia was maintained, as high irrigation rates are able to meet increased evaporative demand (Puma and Cook 2010; Cook et al. 2011). This is consistent with the 'masking' of increased temperatures due to GHG forcing over South Asia, which could impact SASM development in the future (Sen Roy et al. 2007, 2010). This surface cooling is also comparable to the observed warming of equatorial Indian SSTs and these combined effects could weaken the SASM circulation and moisture flux. Furthermore, it has been suggested that irrigation effects must be included in order to reproduce components of the SASM and its response to a warmer climate (Saeed et al. 2009).

These irrigation-induced changes in South Asian surface energy balance may impact the large-scale monsoonal circulation, by way of a weakened land-sea temperature gradient. Many of the previous studies focus on the impact of irrigation on surface temperature and monsoonal rainfall-important quantities for many a livelihood in South Asia. However, an analysis of how intensifying South Asian irrigation have impacted the evolution of the large-scale SASM circulation over the twentieth century has not yet been attempted. Here, we conduct new GCM experiments to investigate the impact of irrigation intensity on the historical evolution of the SASM circulation. We focus on two research questions: (1) How has increasing irrigation affected the strength and variability of the twentieth century SASM circulation? (2) How do the irrigation impacts compare to those of increased GHG forcing and warmer regional SSTs?

\section{Methodology}

\subsection{Model description}

For our simulations, we use the Goddard Institute for Space Studies (GISS) ModelE-R, an atmospheric GCM coupled 
to the Russell-Schmidt dynamic ocean model (hereafter referred to as ModelE). ModelE was run at $2^{\circ} \times 2.5^{\circ}$ (latitude $\times$ longitude) resolution with 40 vertical layers in the atmosphere and 32 layers in the ocean. The version of ModelE utilized here was frozen for IPCC Fifth Assessment Report, and builds upon the version of ModelE discussed in detail in Schmidt et al. (2006) and Hansen et al. (2007), related to climate simulations from 1880 to 2000. This version also exhibits improvements in cloud parameterizations and in the model code for sea-ice, ocean dynamics and the land-surface (Schmidt et al., in prep). The land surface is divided into vegetated and bare soil columns, extending to a depth of $3.5 \mathrm{~m}$. Vegetation and phenology is prescribed (Matthews 1983, 1984) for eight vegetation types, distinguishing for its photosynthesis and stomatal conductance calculations using functions detailed in Farquhar et al. (1980) and Ball et al. (1987). Hansen et al. (2007) demonstrated that ModelE is able to reproduce the twentieth century climate, including trends, low and high frequency variability, when forced with observed SSTs.

Wisser et al. (2010) estimated irrigation rates for the twentieth century as part of a reconstruction of twentieth century global hydrography. These authors produced their estimates by first using the University of Frankfurt/Food and Agriculture Organization Global Map of Irrigated Areas (Siebert et al. 2005a, b) to identify the areas equipped for irrigation at a spatial resolution of 5 arc minutes for the turn of the twentyfirst century (around the year 2000). From this map, they created a time series of irrigated areas in each grid cell extending back to 1901 by rescaling the year 2000 values with time series of irrigated area at the country level (compiled by Freydank and Siebert 2008). Prior to 1950, country level data on areas equipped for irrigation were unavailable for many locations. In these cases, Freydank and Siebert (2008) linearly extrapolated back to 1900 . Using these irrigated area data, estimates of monthly irrigation rates were obtained using a water balance and transport model (WBMplus) (e.g., Federer et al. 2003). See Wisser et al. (2010) for further details.

Water for irrigation is added to the top of the soil column in the vegetated fraction of the grid cell (beneath the vegetation canopy). Surface water reservoirs (rivers and lakes) supply the initial irrigation in the same grid cell. In the event that the irrigation demand is not satisfied by these sources, water is then added to the system under the assumption that it is taken from groundwater sources that are not represented in the model. The flux of water is kept constant over the course of the day for days with non-zero irrigation, and is applied at every time step. Applied irrigation water can either infiltrate the soil column (where it can then leave as evapotranspiration) or leave the grid cell as runoff. Additional details on the implementation of the irrigation scheme in ModelE can be found in Puma and Cook (2010) and Cook et al. (2011).

\subsection{Description of simulations and analysis}

We present results from four experiments performed with ModelE coupled to the Russell-Schmidt dynamic ocean model. Results from the four experiments are an ensemble average of five independent ensemble members all using the same respective forcings but with different initial conditions. For each member simulation, the model is started from an equilibrium state at 1850 , following a spinup period of 1,000 years. The simulations are analyzed for the 1960-2001 interval. The first simulation is a "Control" simulation in which all forcings are set to 1850 levels throughout the simulation and time-varying irrigation is not included. The second simulation, "GHG_only", is performed with transient twentieth Century GHG and other forcings, but without time-varying irrigation. Also included are time-varying land surface specifications, however, we are not specifically assessing the effects of land-use change. The third simulation, "IRR_only", includes timevarying irrigation over the twentieth Century, but all other forcings, including GHGs, are set to 1850 levels. Finally, the fourth simulation "GHG + IRR" applies both timevarying irrigation and all other transient twentieth Century forcings, including GHG concentrations and the resulting increases in equatorial Indian Ocean SSTs, which are comparable to the observed Hadley Sea Ice and Sea Surface Temperature (Shukla 2011). Table 2 provides a brief description of each model simulation discussed here along with their respective forcings. Figure 1 shows the ModelE specified irrigation requirements (or total irrigation water

Table 2 ModelE experiments and description of forcings

\begin{tabular}{lll}
\hline Simulation abbrev. & Irrigation & Forcings \\
\hline Control & No & GHG, solar, volcanoes and aerosols set to 1850 \\
GHG_only & No & Twentieth century GHG, solar, volcanoes and aerosols \\
IRR_only & Yes, time varying & GHG, solar, volcanoes and aerosols set to 1850 \\
GHG + IRR & Yes, time varying & Twentieth century GHG, solar, volcanoes and aerosols \\
\hline
\end{tabular}

All simulations underwent a spin-period of 1,000 years and were analyzed for the 1961-2001 time interval 
specified in land-surface gridboxes from $5^{\circ}$ to $40^{\circ} \mathrm{N}, 65^{\circ}-$ $\left.95^{\circ} \mathrm{E}\right)$ over the Indian sub-continent during June-September (Monsoon Season), and March-April-May (Pre-Monsoon Dry Season). Totals are higher in the Monsoon Season, due to the greater availability of water via monsoonal rainfall. The total irrigation is less in the PreMonsoon Dry Season, as most irrigation water is sourced from groundwater extractions, but the trend is increasing overall.

\section{Results}

\subsection{The SASM circulation: ModelE representation} and comparison of reanalysis products

An important metric used in assessing SASM circulation strength is the Monsoon Intensity (MI) index (Sun et al. 2010; Webster and Yang 1992). The MI index is defined as the difference between the average zonal winds at $850 \mathrm{mb}$ and $200 \mathrm{mb}$ over a region including the northern Indian Ocean and Indian Sub-continent (0-20N, 60E-110E), computed for June-September. The strength of this shearing index is related to the intensity of the latitudinal temperature (and pressure) gradient between the monsoon trough region and the equatorial Indian Ocean. Figure 2a shows the 1960-2001 MI index as calculated from the ERA-40, NCEP twentieth Century and NCEP Climate Diagnostics Center (CDC) Derived Reanalysis products (Kalnay et al. 1996). A significant negative trend (assessed through a Mann-Kendall test at the 0.05 level) is found only in the NCEP CDC Derived product (Fig. 2b), while significant trends are not found in the ERA-40 or twentieth Century products. The NCEP twentieth Century reanalysis product is not as highly correlated with the previous two

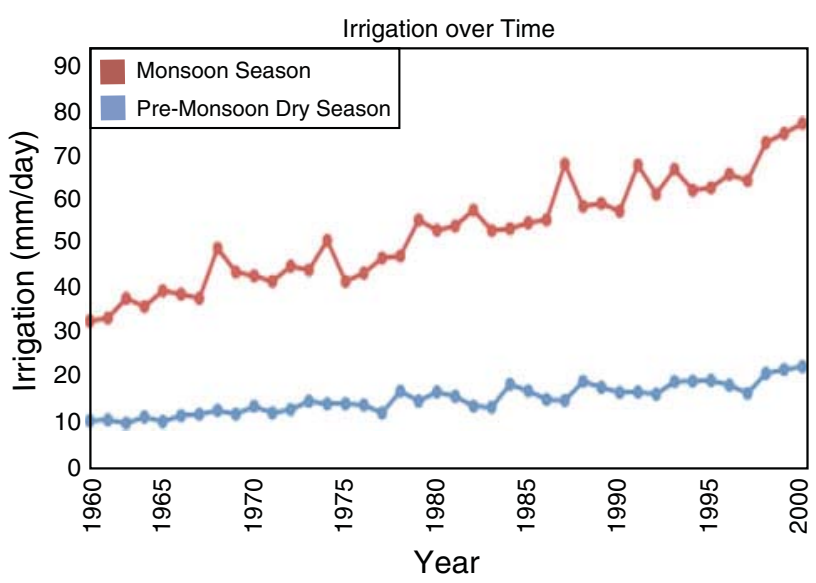

Fig. 1 Irrigation water (mm/day) added over the Indian sub-continent $\left(5^{\circ}-30^{\circ} \mathrm{N}, 60^{\circ}-95^{\circ} \mathrm{E}\right)$ in ModelE for Monsoon Season (red) and pre-monsoon dry season (blue) between 1960 and 2001 products. This discrepancy may be due to the exclusion of upper-level atmospheric temperatures in assimilation of the twentieth Century product (Compo et al. 2011), which are a critical component to the MI index calculation.

ModelE reproduces the SASM's characteristic southwesterly flow from the equatorial Indian Ocean and Arabian Sea during the Monsoon Season (Fig. 3). However, the model underestimates the strength of these winds. When forced with observed SSTs, the ModelE MI index is correlated to reanalysis-calculated MI indices, particularly the NCEP CDC Derived (Pearson's $r=0.71$ ). It is known that ENSO phases are related to a considerable amount of variability in the SASM as well, and the CDC Derived MI index has a 0.41 correlation with the SOI from 1960 to 2001. ModelE (with prescribed SSTs) also produces a similar correlation to the SOI $(\mathrm{R}=0.44)$.

However, the coupled ModelE does not reproduce the full MI as depicted by any of the reanalysis products, and thus, produces an overall weaker monsoonal circulation (Fig. 2). This may be related, in part, to a cold bias that ModelE displays at higher altitudes over the northern Indian region relative to various reanalysis products, which can weaken the latitudinal temperature contrast that initially drives the SASM circulation. Yet, the model is able to simulate the gross features of the SASM, and, most notably, it is able to simulate the magnitude and the overall variability of the All-India Rainfall (Parthasarathy et al. 1995), shown in Fig. 4a. The model also reproduces known areas of maximum rainfall during the monsoon period, over the northern Bay of Bengal and over the Kerala coast (Fig. 4b, c). However, the model overestimates the rainfall in these areas and underestimates the rainfall in the interior of India. While the modeled total All-India rainfall is similar to the observed, the geographic distribution of rainfall is not fully reproduced.

\subsection{Monsoon intensity}

The ModelE simulations do not reproduce the full magnitude or variability of the MI index shown in the various reanalysis products (Fig. 2a). When a Mann-Kendall test of significance was performed, no declining trend in MI was found in any of the ModelE simulations (Fig. 2b). Interestingly, prescribed (atmosphere-only) SST ModelE simulations with twentieth century GHG forcings and irrigation display significant declining trends (not shown here). While the GHG_only and Control simulations show an MI index with a greater standard deviation than any of the reanalysis products (see Table 3 for standard deviations), the GHG_only and Control simulations' standard deviations were not found to be significantly different from the reanalysis products according to an $F$-test that checks for differences in variability. However, the IRR_only and 
Fig. 2 a Monsoon intensity (MI) index (m/s) from 1960 to 2001 (domain bounded by $0-20^{\circ} \mathrm{N}, 60^{\circ}-110^{\circ} \mathrm{E}$ ) shown for the reanalysis products (ERA40-light blue, NCEP CDC Derived-red and NCEP twentieth Century-purple) and ModelE simulations

$(\mathrm{GHG}+\mathrm{IRR}$ simulation-dark blue, GHG_only_green, IRR_only-orange and Control-gray). b MI index trend for 1960-2001 shown for each reanalysis product and ModelE simulation, in their respective colors. The "*” denotes significant trends, evaluated by a Mann-Kendall test at the 0.05 level. The standard deviation for each series is shown in Table 3
Monsoon Intensity Index

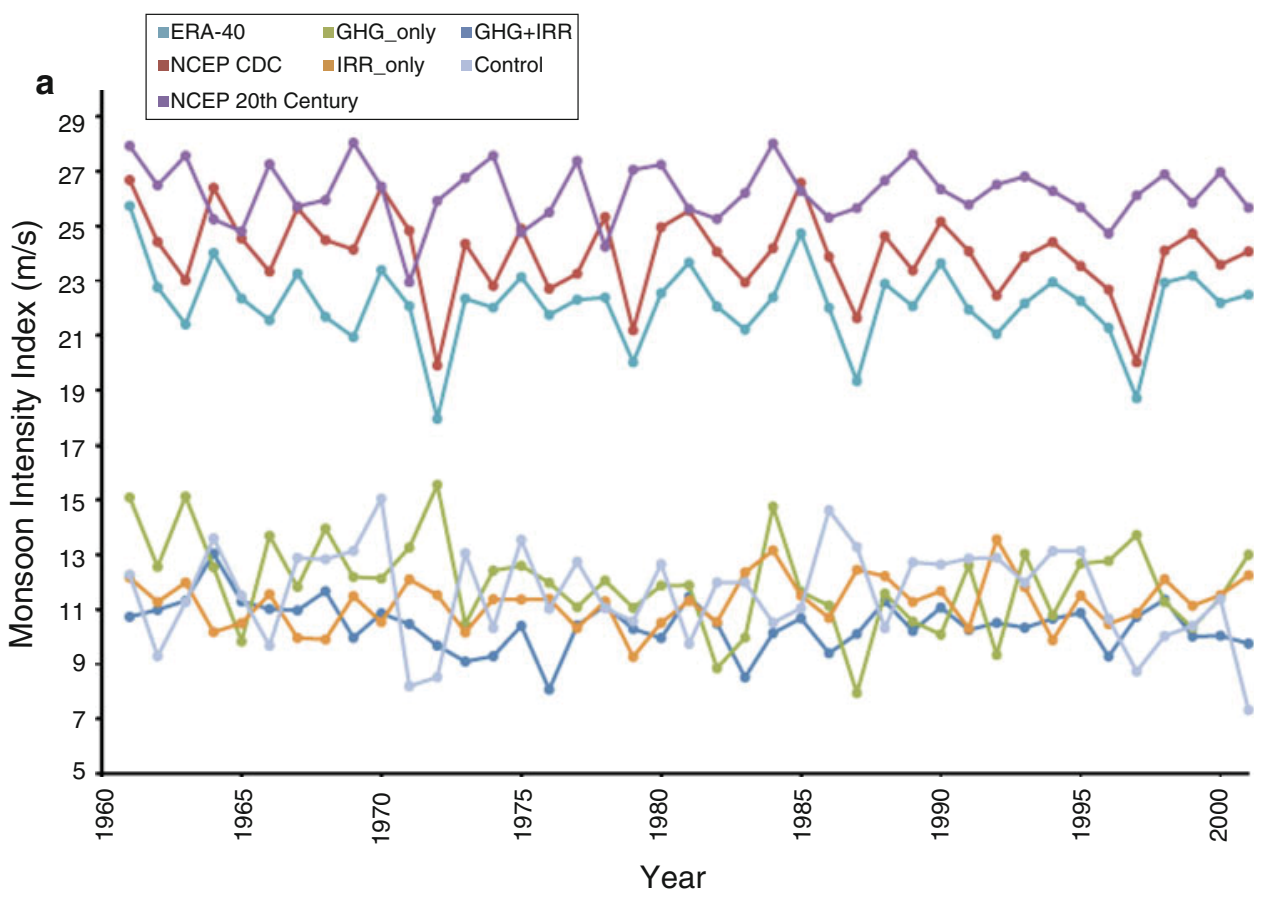

b

Trends in the Monsoon Intensity Index

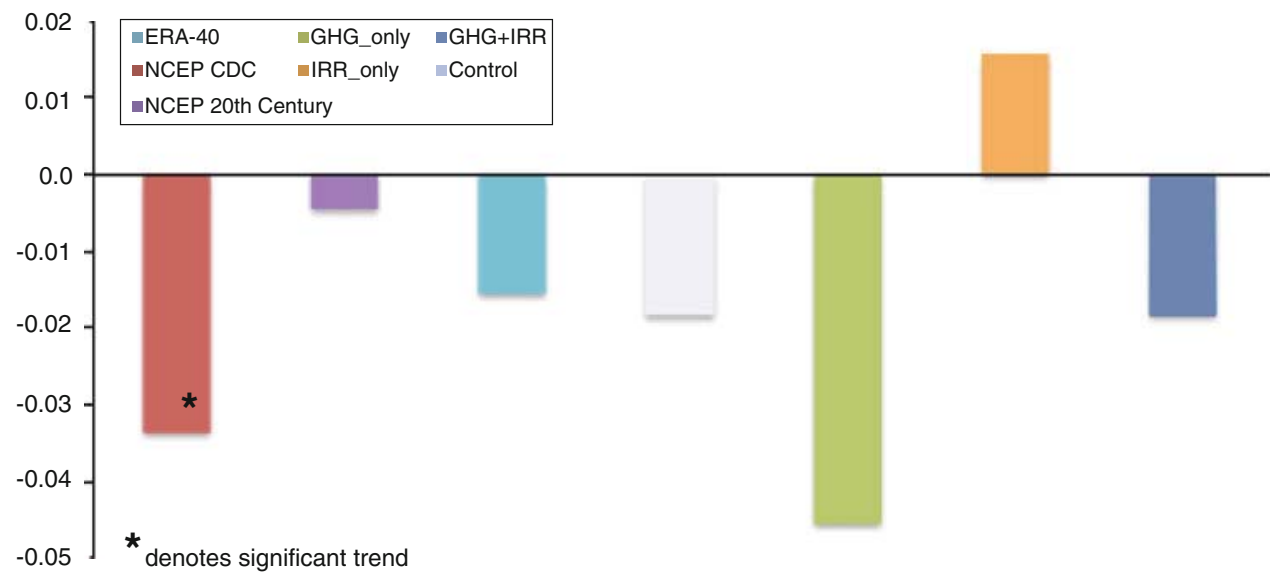

the GHG + IRR simulations did display reduced MI variability from the Control and GHG_only runs.

To assess how MI variability changes with time, 10-year moving coefficients of variation (CV) are computed for each simulation's MI index (Fig. 5a). The non-irrigated simulations distinctly differ from the reanalysis products and irrigated simulations, both in their range of $\mathrm{CV}$ and the trend in variability. The reanalysis products and ModelE simulations showed the following significant 1960-2001 trends in their CVs (via a Mann-Kendall test at the 0.05 level): $\quad \mathrm{CDC} \quad$ Derived $=-0.056$; twentieth Century $=0.119 ; \quad$ ERA40 $=-0.024 ; \quad$ Control $=-0.259$; GHG_only $=0.097$; IRR_only $=0.064 ; \mathrm{GHG}+\mathrm{IRR}=$ -0.135 (Fig. 5b). The irrigated simulations produce $\mathrm{CV}$ ranges more consistent with the reanalysis products. However, the GHG + IRR simulation, which also included the GHG warming equatorial Indian Ocean SSTs, is most consistent with all the reanalysis products in that it produces both a significant declining trend and a more limited range in $\mathrm{CV}$.

\subsection{Lower-level and upper-level land-sea temperature contrast}

The Monsoon Season lower-level and upper-level temperature contrasts between the Indian sub-continent and the equatorial Indian Ocean are critical to the initial development of the large-scale SASM circulation and MI. The upper-level 
Fig. $3850 \mathrm{mb}$ Monsoon Season zonal winds $(\mathrm{m} / \mathrm{s})$ averaged over the period 1960-2001, for a NCEP CDC Derived reanalysis and $\mathbf{b}$ the coupled ocean-atmosphere ModelE GHG_only run. In both maps, red areas (such as over the northern Indian Ocean) indicates westerly flow, while blue areas indicate easterly flow
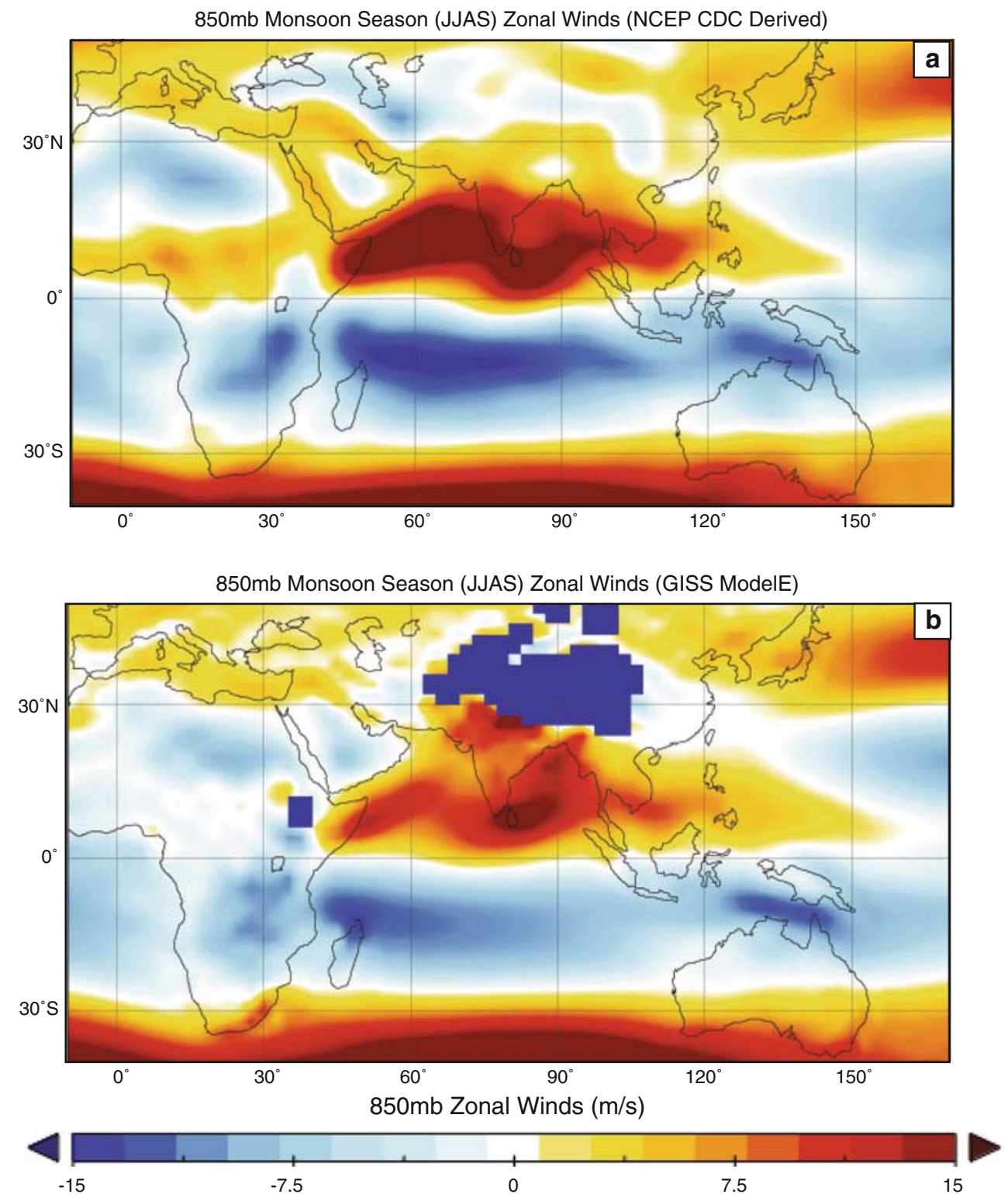

temperature contrast is calculated as the difference in the 200-500 mb thickness temperature between the northern Indian continent and equatorial Indian Ocean. The lower-level temperature contrast is calculated as the difference in the near surface temperatures over the northern Indian continent and the 500-800 mb thickness temperatures over the equatorial Indian Ocean (Sun et al. 2010). The northern Indian continent region is bound by $20^{\circ}-40^{\circ} \mathrm{N}, 60^{\circ}-100^{\circ} \mathrm{E}$, while the equatorial Indian Ocean is bound by $10^{\circ} \mathrm{S}-10^{\circ} \mathrm{N}, 60^{\circ}-100^{\circ} \mathrm{E}$. Sun et al. (2010) found that the MI index was strongly correlated with the upper-level temperature contrast (Pearson's $r=0.84$ ) and moderately correlated with the lower-level temperature differentials (Pearson's $r=0.51$ ). The simulated MI indices for the GHG + IRR and GHG_only runs correlated with the upper-level temperature contrast by 0.76 and 0.74 , respectively. For the IRR_only and Control runs, the correlations with the upper-level temperature contrast were 0.78 and 0.73 , respectively. Correlations between the lower-level temperature contrast and $\mathrm{MI}$ index were $\mathrm{r}=0.53$ for the Control run; 0.27 for the IRR_only run; 0.34 for the GHG_only run and 0.49 for the GHG + IRR run. Irrigation can change the surface energy balance, and thus are strongly (negatively) correlated to the low-level temperatures. Correlations between the IRR_only and GHG + IRR irrigation and lower- and upper-level atmospheric temperature contrasts are noted in Table 4. The strongest correlation between irrigation and the lower-level temperature contrast exists during the Monsoon Season, although the correlation is also relatively high during the Pre-Monsoon Dry Season.

The introduction of irrigation cools the land surface temperature in both the IRR_only and GHG + IRR simulations when compared to the Control and GHG_only 


\section{All-India Monsoon Season Rainfall}
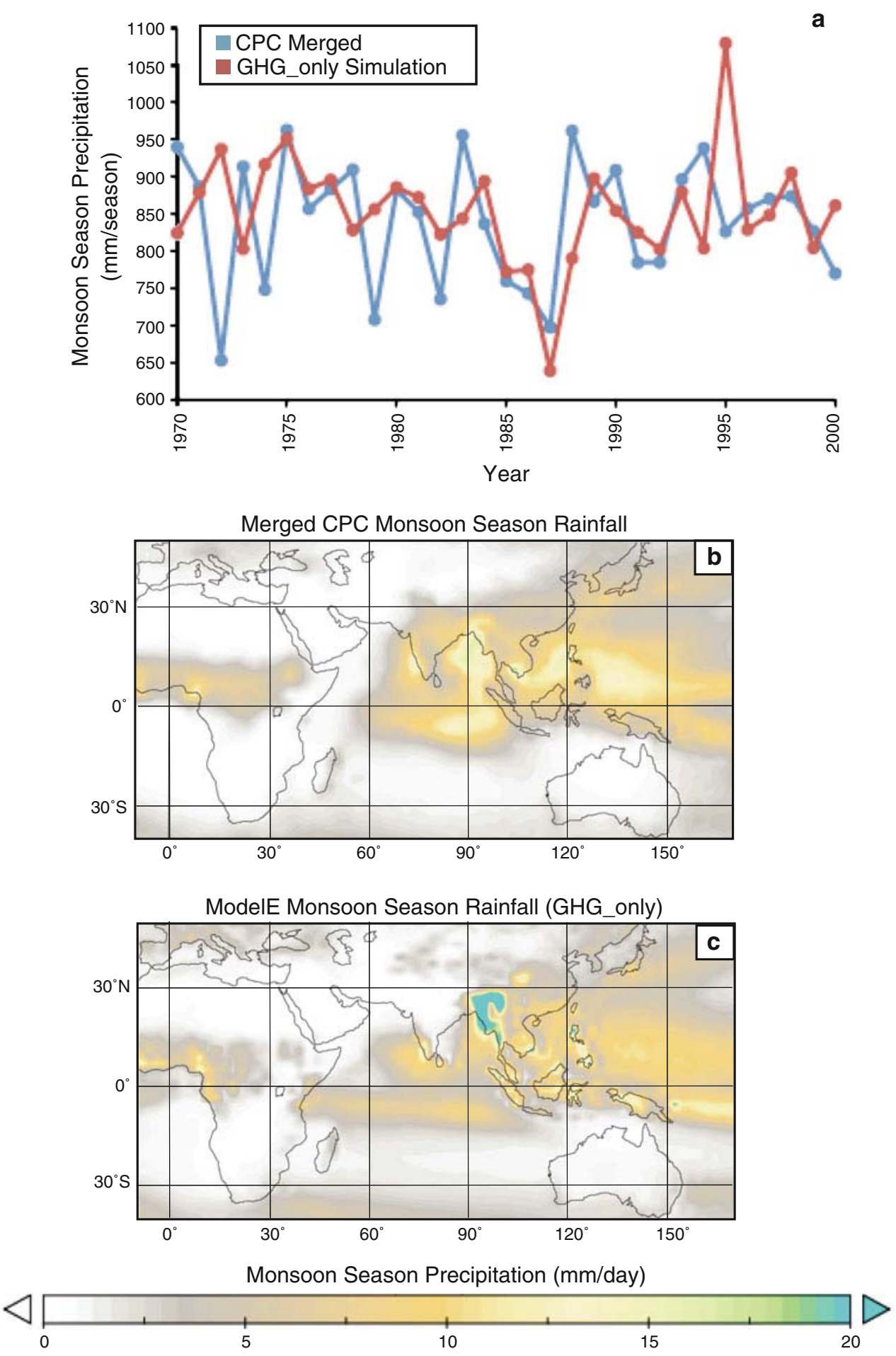

Fig. 4 a The All-India Monsoon Rainfall index (from 306 Indian weather stations, averaged over June-July-August-September) shown from 1960 to 2001 for the Merged CPC analysis (blue) and the ModelE GHG_only simulation (red). Monsoonal Season (June-

simulations, respectively (Fig. 6a, b). The cooling is prominent over the (western) Indo-Gangetic Basin, corresponding to the most intensively irrigated areas. The
July-August-September) Rainfall (mm/day) total averaged between 1960 and 2001 for $\mathbf{b}$ merged CPC analysis and $\mathbf{c}$ the coupled oceanatmosphere ModelE GHG_only

$300 \mathrm{mb}$ layer also displays a cooling (Fig. 6c, d) relative to the non-irrigated simulations, despite lesser correlations between the upper-level temperature contrast and surface 
Table 3 Standard deviations of monsoon intensity (MI) index

\begin{tabular}{ll} 
Time series of monsoon intensity index $(\mathrm{m} / \mathrm{s})$ & Standard deviation \\
\hline NCEP CDC derived & 1.54 \\
NCEP twentieth century & 1.09 \\
ECMWF ERA-40 & 1.44 \\
GHG + IRR & 0.89 \\
GHG_only & 1.69 \\
IRR_only & 0.92 \\
Control & 1.76 \\
\hline
\end{tabular}

irrigation. The cooling at altitude is more pronounced in the GHG + IRR simulation, which also includes the GHGinduced warming of equatorial Indian SSTs that raise atmospheric temperatures above the sea surface. Figure 7 a shows the lower-level temperature contrast over time for each of the ModelE simulations. The IRR_only and GHG + IRR simulations display significant declining trends (assessed by Mann-Kendall tests at 0.05 level) with time (Fig. 7b), while no significant trends are shown in the non-irrigated simulations. Figure $7 \mathrm{c}$ indicates that as irrigation increases, the lower-level temperature contrast
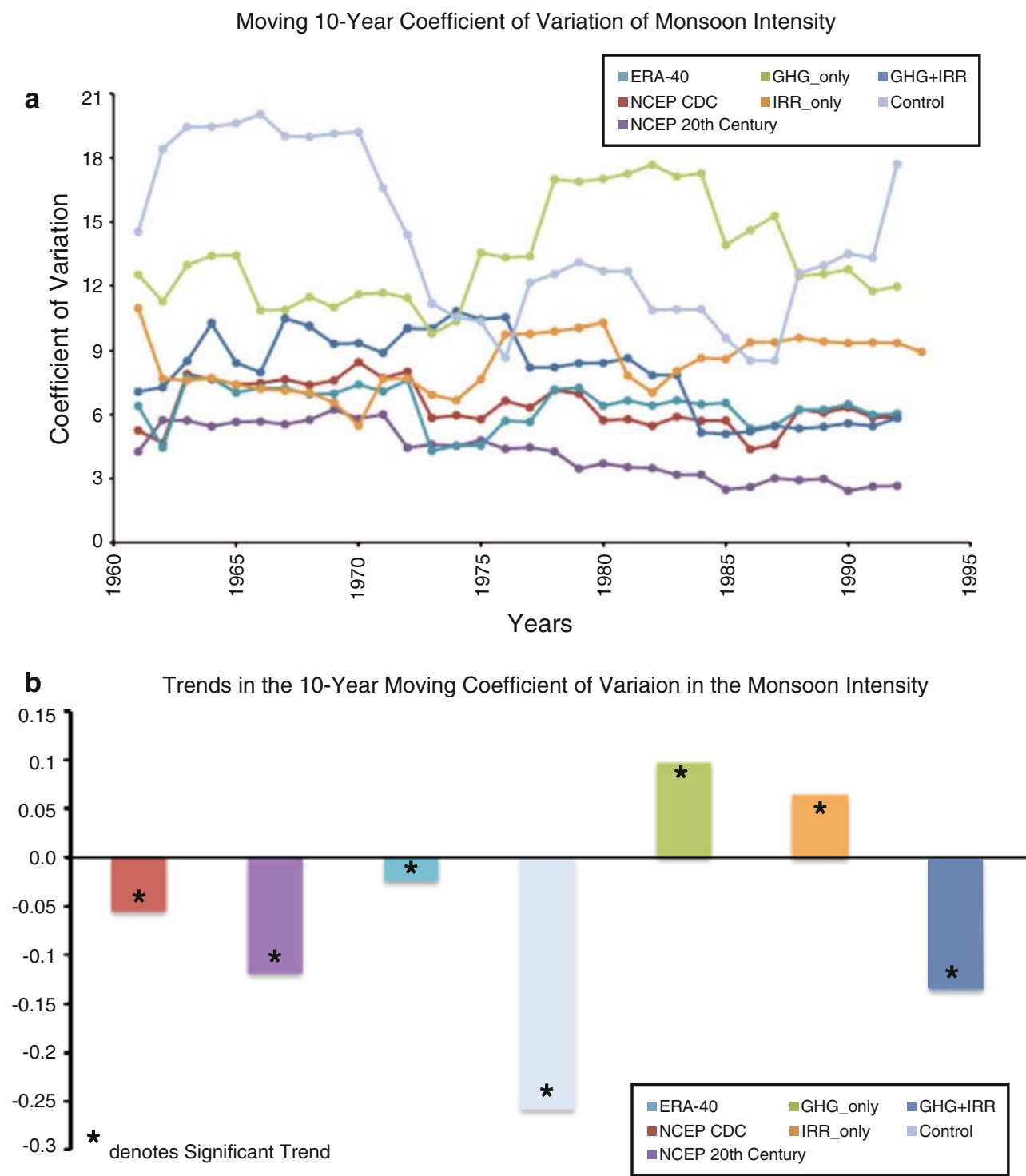

Fig. 5 a 10-Year moving coefficient of variation $(\mathrm{CV})$ in the monsoon intensity index from 1960 to 2001 (domain bounded by $0-20^{\circ} \mathrm{N}, 60^{\circ}-110^{\circ} \mathrm{E}$ ), shown for the reanalysis products (ERA-40light blue, NCEP CDC Derived-red and NCEP twentieth Centurypurple) and ModelE simulations (GHG + IRR simulation-dark blue, GHG_only-green, IRR_only-orange and Control-gray). b 1960-2001 Trends in the 10-year moving CV shown for each reanalysis product and ModelE simulation, in their respective colors. The "*" denotes significant trends, evaluated by a Mann-Kendall test at the 0.05 level 
Table 4 Pearson's $r$ correlation coefficient between irrigation requirements and atmospheric temperature contrast

\begin{tabular}{|c|c|c|c|c|}
\hline \multirow[t]{2}{*}{ Simulation } & \multicolumn{2}{|l|}{ Pre-monsoon dry season } & \multicolumn{2}{|l|}{ Monsoon season } \\
\hline & $\begin{array}{l}\text { Upper-level temperature } \\
\text { contrast }\end{array}$ & $\begin{array}{l}\text { Lower-level temperature } \\
\text { contrast }\end{array}$ & $\begin{array}{l}\text { Upper-level temperature } \\
\text { contrast }\end{array}$ & $\begin{array}{l}\text { Lower-level temperature } \\
\text { contrast }\end{array}$ \\
\hline$\frac{\text { IRR_only irrigation }}{\text { requirements }}$ & -0.34 & -0.57 & -0.46 & -0.66 \\
\hline$\frac{\text { GHG + IRR irrigation }}{\text { requirements }}$ & -0.42 & -0.64 & -0.46 & -0.72 \\
\hline
\end{tabular}

decreases in both irrigated simulations. The lower-level temperature contrast is generally weaker in the GHG + IRR simulation than in the IRR_only simulation.

Between the last and first decades of the GHG + IRR simulation, variability decreases by $37 \%$ in the lower-level temperature contrast and $48 \%$ in the upper-level temperature contrast. In the IRR_only simulation, the lower-level temperature contrast does not display a significant decrease in its standard deviation between the first and last decades. A $16 \%$ decrease is produced between the first and last decades of the upper-level temperature contrasts. Only the GHG + IRR simulation displays significant decreasing trends (according to a Mann-Kendall test) in the 10-year moving CVs of the upper-level and lower-level temperature contrasts (Fig. 8a, b), suggesting decreases in variability since 1961 . The decline is especially notable in the GHG + IRR lower-level temperature contrast. The IRR_only simulation, however, does not show the same degree of variation or significance of trend in the $\mathrm{CV}$ for the upper or lower-level temperature contrasts.

\subsection{Surface energy balance and moisture flux}

Large decreases in the Bowen ratio, representing increased latent heat flux (LHF), are shown over the most heavily irrigated areas in the IRR_only and GHG + IRR simulations (relative to their respective non-irrigated runs), particularly in northern India/Pakistan (Fig. 9a, b). The increase in modeled surface evaporation is comparable to the amount of irrigation water added (about $2 \mathrm{~mm} /$ day in May before SASM onset, for example) with negligible runoff (not shown). Such partitioning is consistent with the results for water-limited regions produced from studies regionally focused on South Asia, such Douglas et al. (2009).

Increased LHF does not, however, necessarily result in an increased Monsoon Season rainfall. There is an increase in the simulated atmospheric water vapor over the most heavily irrigated areas in both irrigated simulations. The GHG + IRR and IRR_only simulations both show decreases in the meridional water vapor transport (Fig. 10a, b) over the northern Indian Ocean and Arabian Sea, which largely contribute to the Monsoon Season moisture convergence over the Indian continent. These decreases result in part from weakened lower-level wind fields in both simulations.

\section{Discussion and conclusions}

Agricultural intensification and increasing surface irrigation can be considered a forcing on regional climates. This study assessed the specific contribution of intensifying irrigation over the 20th century on the SASM circulation through analysis of the MI index and the driving land-sea temperature contrasts. Coupled GCM simulations were performed using time-varying irrigation specifications alone and in combination with GHG forcing. For each simulation, the magnitude and variability of the MI index, lower and upper-level temperature contrasts were evaluated along with the changes in the surface energy balance and moisture transport. The simulations were also compared with three reanalysis products, which were themselves evaluated for mutual consistency.

\subsection{Impacts on the South Asian Summer Monsoon intensity}

ModelE is consistent with the ERA-40 and NCEP twentieth Century reanalysis products in that it does not produce a decline in the MI over the 1960-2001 interval. ModelE does not produce the full magnitude of the MI indicated in reanalysis products. However, the irrigated simulations produce MI variability that is more consistent with the reanalysis products and significantly decreased relative to the Control and GHG_only simulation.

The variance in the MI index decreases at higher irrigation rates (found towards the end of the twentieth century, as irrigation intensifies with time). The irrigated simulations show 10-year moving CVs that are more consistent with the three reanalysis products (all showing significant declining trends in variability), which suggests that the inclusion of irrigation may be necessary to accurately simulate the historical trends and variability of the SASM system over the last 50 years - a finding consistent with the regional climate studies performed by Saeed et al. (2009). 
Fig. 6 Pre-Monsoon Dry Season (MAM) surface air temperatures $\left({ }^{\circ} \mathrm{C}\right)$ for the a IRR_only and b GHG + IRR simulations, differenced with the Control and GHG_only simulations, respectively. PreMonsoon Dry Season (MAM) $300 \mathrm{mb}$ temperatures $\left({ }^{\circ} \mathrm{C}\right)$ are shown for c IRR_only and d GHG + IRR simulations, differenced with the Control and GHG_only simulations, respectively
Pre-Monsoon Dry Season Surface Temperature
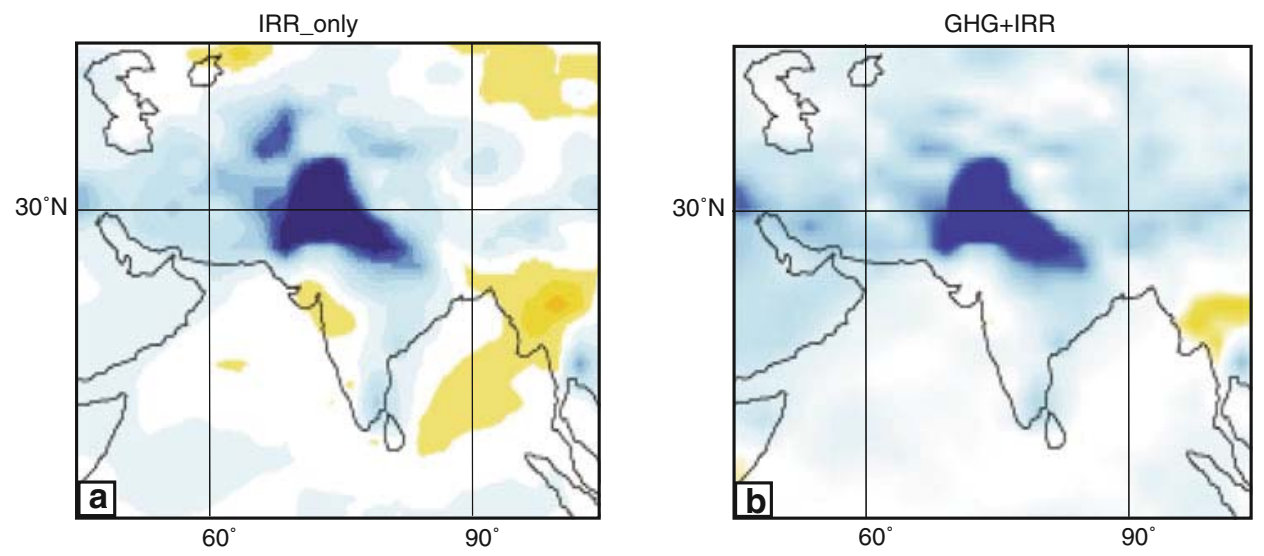

May Surface Temperature $\left({ }^{\circ} \mathrm{C}\right)$
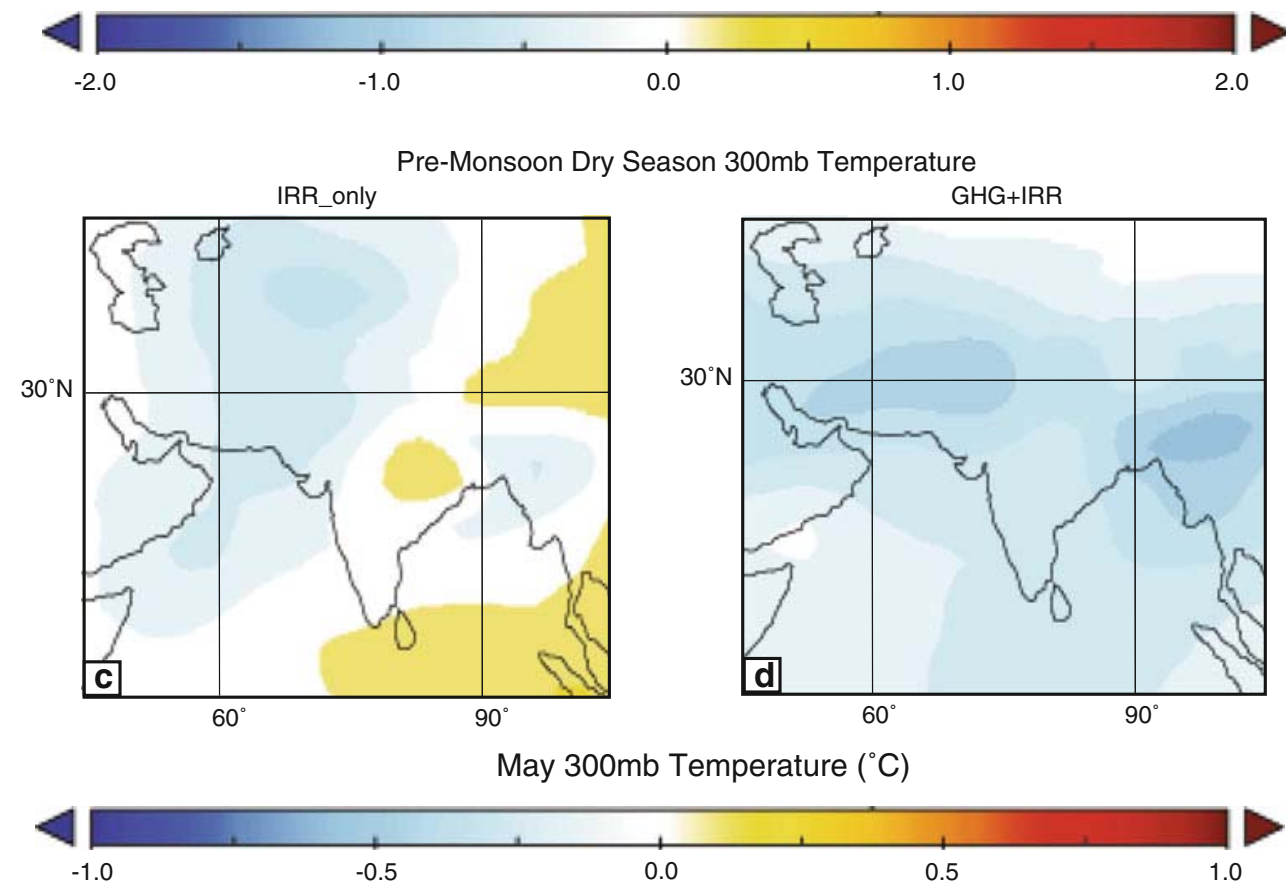

amount. Longer time series of the relevant SASM variables may be needed to assess the significance of these findings in the context of SASM variability. However, the implications for less variable monsoons (particularly if rainfall is weakened) are relevant and extend to studies of predictability-a topic of prime importance in SASM research.

\subsection{Impacts to the lower- and upper-level land-sea temperature contrasts}

Significant trends were shown in the temperature contrasts between the Indian continent and the equatorial Indian Ocean, particularly in the lower-levels of the atmosphere and in the GHG + IRR simulation. As moderate-to-strong correlations exist between the MI index and the upper- and lower-level temperature contrasts, the variability in these 


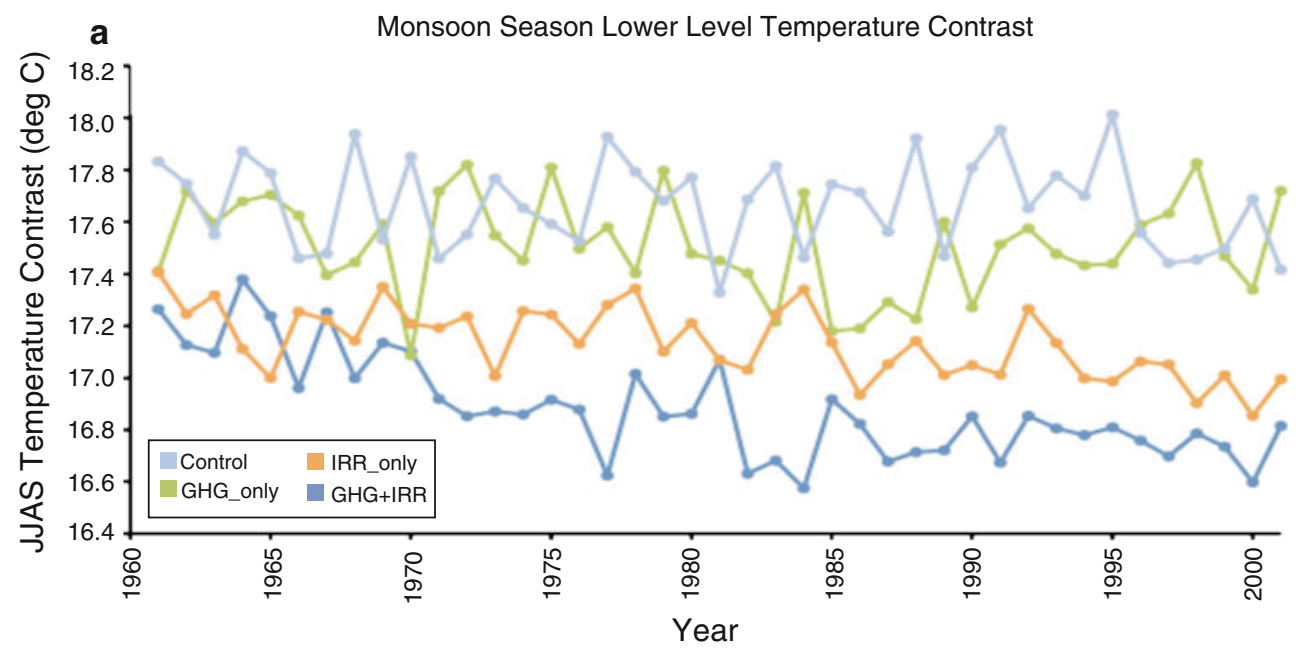

b
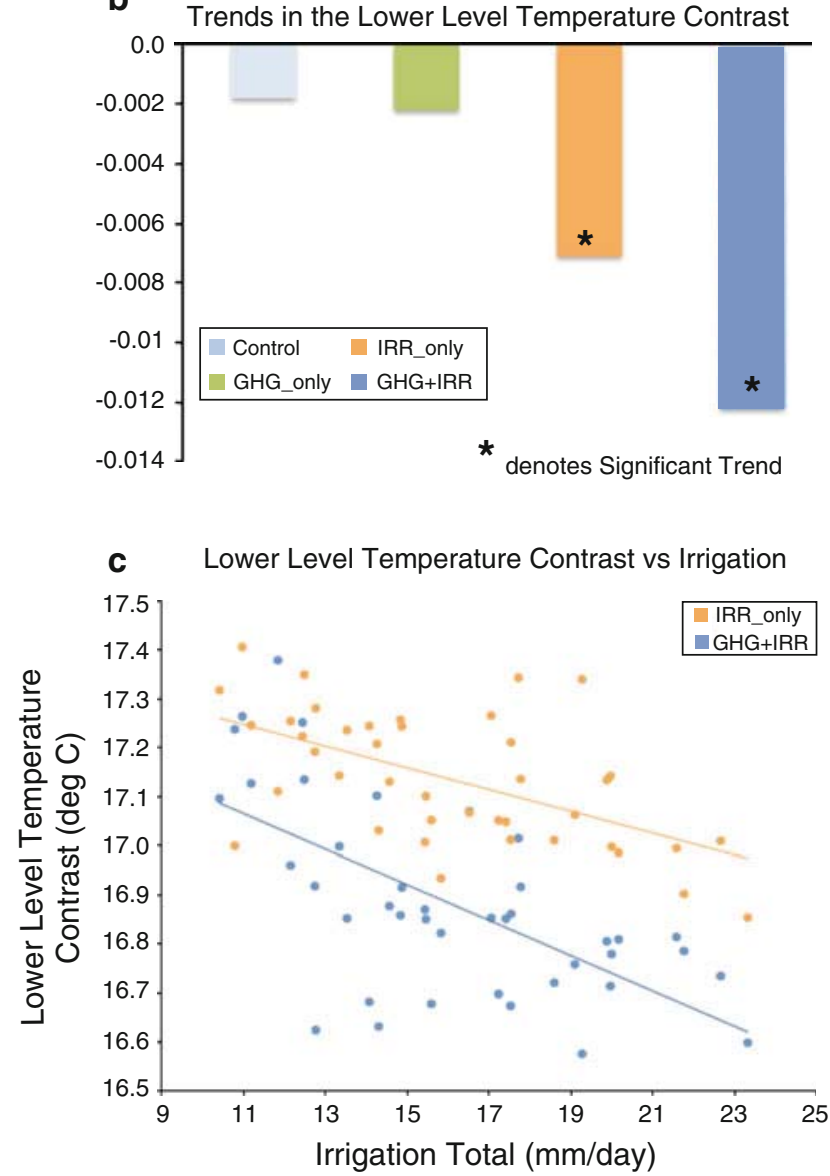

Fig. 7 a The Monsoon Season lower-level (800-500 mb) temperature contrast $\left({ }^{\circ} \mathrm{C}\right)$ between the northern Indian continent $\left(20^{\circ}-40^{\circ} \mathrm{N}\right.$, $\left.60^{\circ}-100^{\circ} \mathrm{E}\right)$ and the equatorial Indian Ocean $\left(10^{\circ} \mathrm{S}-10^{\circ} \mathrm{N}, 60^{\circ}-100^{\circ} \mathrm{E}\right)$ from 1960 to 2001. Shown for the ModelE Control simulation (grey), the GHG_only simulation (green), the IRR_only simulation (orange) and the GHG + IRR simulation (dark blue). b 1960-2001 Trends in

quantities may also be related. The MI index's decline in variability is consistent with the modeled trends in the temperature contrasts, particularly when GHG forcing is the lower-level temperature contrast shown for each reanalysis product and ModelE simulation, in their respective colors. The "*" denotes significant trends, evaluated by a Mann-Kendall test at the 0.05 level. c The Monsoon Season lower-level temperature contrast $\left({ }^{\circ} \mathrm{C}\right)$ versus irrigation $(\mathrm{mm} / \mathrm{day})$ for the ModelE IRR_only (orange) and the GHG + IRR simulation (dark blue)

included. The lower-level temperature contrast, which is more directly impacted by changes in surface energy balance, shows decreases in both its magnitude and variability 
Fig. 8 Monsoon Season 10 -year moving coefficients of variation in the temperature contrast between the northern Indian continent $\left(20^{\circ}-40^{\circ} \mathrm{N}\right.$, $\left.60^{\circ}-100^{\circ} \mathrm{E}\right)$ and the equatorial Indian Ocean $\left(10^{\circ} \mathrm{S}-10^{\circ} \mathrm{N}, 60^{\circ}-\right.$ $\left.100^{\circ} \mathrm{E}\right)$ from 1960 to 2001 for the a lower-level (800-500 mb) temperature contrast and b upper-level (500-200 mb) temperature contrast. In both (a) and (b), the IRR_only simulation is shown in red, and the GHG + IRR simulation is shown in blue
Fig. 9 Pre-Monsoon Season (MAM) Bowen Ratio for the a IRR_only simulation differenced with the Control simulation and $\mathbf{b}$ the GHG + IRR simulation differenced with the GHG_only simulation
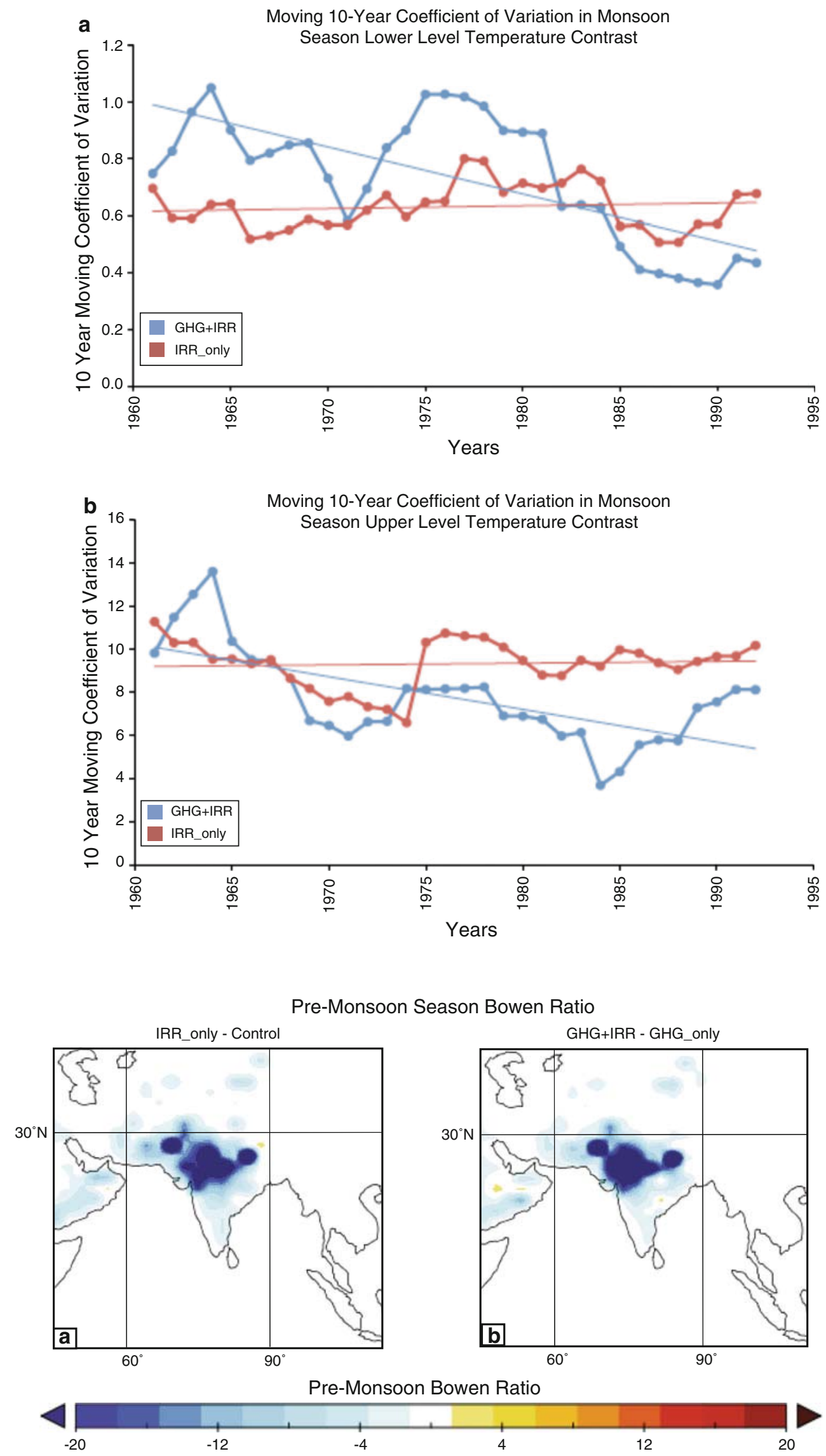
Monsoon Season Meridional Water Vapor Transport
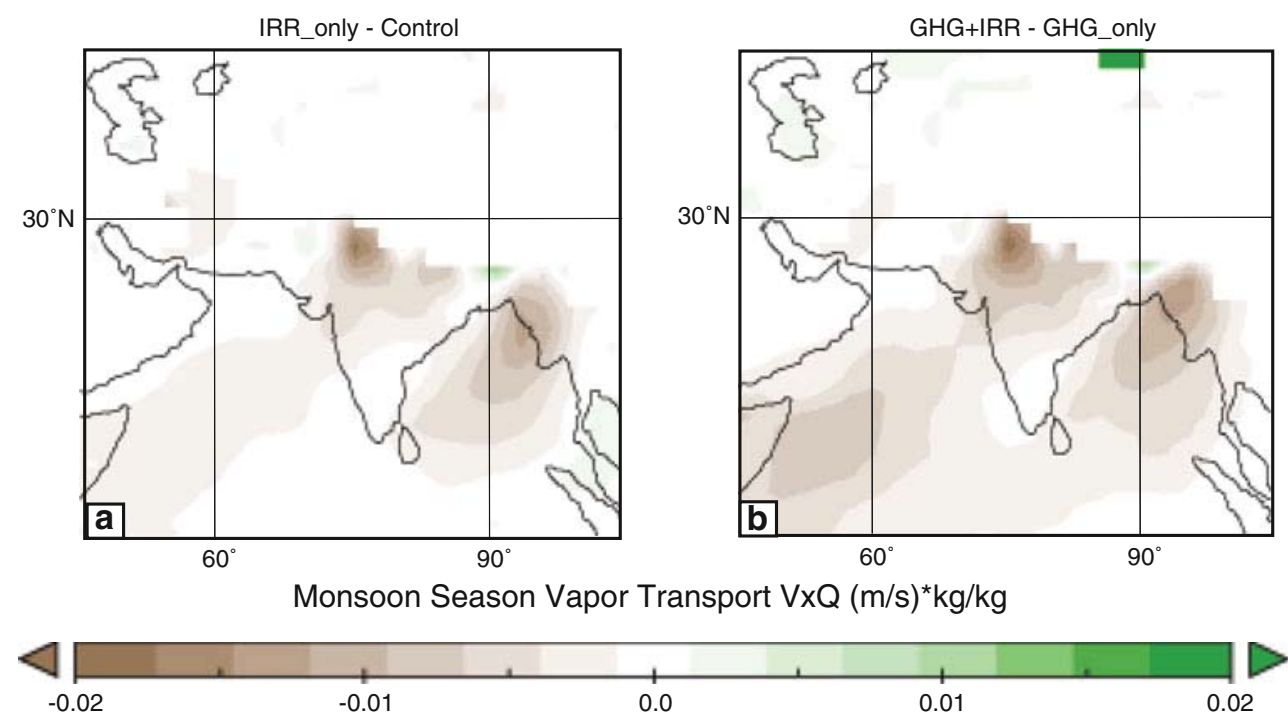

Fig. 10 Monsoon Season (JJAS) meridional water vapor transport $((\mathrm{m} / \mathrm{s}) * \mathrm{~kg} / \mathrm{kg})$ at $875 \mathrm{mb}$ for the a IRR_only simulation differenced with the Control simulation and $\mathbf{b}$ the GHG + IRR simulation differenced with the GHG_only simulation

under irrigation. Its decline may significantly contribute to limiting MI index variability.

The yearly Monsoon Season LHF is strongly correlated to the lower-level temperature contrast (Pearson's $r=0.85$ ), highlighting the impact that changes in surface energy balance have on the monsoon circulation. The moderately strong correlations between the Monsoon Season lower-level temperature contrasts and the PreMonsoon Dry Season irrigation suggest that the dry-season irrigation partly inhibits the build-up of the lower-level temperature gradient. This may be particularly acute over the dry, water-limited northern Indian sub-continent, as water added for irrigation in the pre-monsoon season can evaporate efficiently, cooling the surface. Furthermore, although irrigation alone does not produce a significant trend in the upper-level temperatures, there is still a decline in the upper-level 10-year moving CV (though the impact is weaker compared to the low-level temperature contrasts). The GHG + IRR simulation produced greater significant declines in the moving $\mathrm{CV}$ than IRR_only simulation, which indicates that GHG forcing, particularly in its warming of Indian Ocean SSTs, can act in concert with irrigation to further attenuate monsoon variability. Less variability and weakening of the temperature contrasts, both at the surface and at altitude, are consistent with the shown decreases MI variability.

\subsection{Impacts to the atmospheric moisture transport} and availability

Under irrigated conditions, the major monsoonal circulatory components are made less variable when compared to the non-irrigated simulations. Both the IRR_only and $\mathrm{GHG}+\mathrm{IRR}$ irrigated simulations produce weaker lowlevel southwesterly winds. This indicates that even irrigation alone can weaken components of the monsoonal circulation. Weaker SASM winds partially result from the significant decline in the lower-level temperature contrast and the cooling at upper atmospheric levels over the monsoon trough region when intensified irrigation is present.

Weaker SASM low-level winds would also impact lowlevel moisture transport, which is evidenced here. Atmospheric water content is increased over the heavily-irrigated Indo-Gangetic Basin. However, our results indicate that the southwesterly water vapor transport from the northern Indian Ocean and Arabian Sea is weakened under irrigated conditions, particularly in the GHG + IRR simulation. Coupled with reductions in atmospheric water vapor over the Indian peninsula, this result indicates that both increased irrigation and GHG forcing impact decreases moisture transport to the Indian sub-continent. Although slight declines in rainfall occur over the Kerala coast and northern Bay of Bengal, ModelE does not produce declines in rainfall totals or variability that are significantly different from the observed All-India Rainfall average. These results are consistent with the findings of Douglas et al. (2009), and with the changes in the SASM circulation, specifically in the low-level southwesterly winds.

\subsection{Additional contributors to the South Asian Summer Monsoon variability}

This study demonstrated that the intensifying irrigation applications on the Indian sub-continent have potential to 
limit the variability of the MI, decrease the magnitude and variability of the low-level driving monsoonal temperature gradients, and alter atmospheric water vapor transport and moisture fluxes. We also highlighted differences between the ERA-40, NCEP CDC Derived and the NCEP twentieth Century reanalysis products that should be considered when evaluating metrics such as the MI index. The NCEP CDC Derived product displayed a significant declining MI index trend that was not present in the other two reanalysis products. Furthermore, the NCEP twentieth Century product (which does not assimilate upper-level temperatures) did not produce the year-to-year variability that the other two products displayed

It is important to note that the SASM system displays sensitivity to several other regional forcings and feedbacks that could further impact its variability under future climate conditions. Although we did not isolate and separately evaluate each of these forcings, atmospheric pollutants and particulate matter, fluctuations in snow accumulation on the Himalaya, land-use and land-cover changes (beyond irrigation intensification) and changes to natural drivers of regional climate variability (such as the El Niño Southern Oscillation) also contribute to the evolution and strength of the yearly monsoon.

The South Asian region has recently been experiencing the effects of Atmospheric Brown Clouds (ABCs, air pollution clouds consisting of black carbon, sulphates, nitrates, fly ash, etc.) (Ramanathan et al. 2008). ABCs can warm the upper atmosphere, through high-altitude absorption of solar radiation, while cooling the surface. This can lead to further reductions in surface evaporation, shifting the energy balance and reducing the SASM latitudinal temperature gradient. Due to the widespread nature of $\mathrm{ABCs}$ at their peak, this change in energy partitioning can also decrease the vertical transport of water vapor and its availability over the ocean surface, which can lead to decreases in monsoonal rainfall (Cramer 2006). In contrast, other studies have indicated that high-altitude heating, particularly near the Tibetan Plateau, can intensify the heat low and associated pressure gradients responsible for driving the monsoon. Intensified monsoonal circulation may also draw a moisture flux off the ocean surface, which could lead to increases in monsoonal rainfall and changes to monsoonal variability (Lau et al. 2006). Additionally, stronger monsoons have been related to lower winter snow cover and higher winter minimum temperatures (Yanai and $\mathrm{Wu}$ 2006). As winter snow cover becomes more variable in a warmer climate, it may further increase SASM variability. The interaction between irrigation, $\mathrm{ABCs}$ and Himalayan snowfall effects warrants further study to evaluate which is more influential in the region.

In South Asia's most heavily irrigated areas, groundwater and other external irrigation sources may cease to be economically viable in the early-mid twentyfirst century (Jha 2001). Decreased amounts of surface irrigation water, particularly during the dry season could allow for stronger surface warming, again increasing SASM variability and limiting water availability for existing rain-fed crops (as those reservoirs recharged by rainfall are now also used by farmers previously employing groundwater for irrigation).

\subsection{Summary of findings and statement of future work}

Previous studies have suggested decreases to the MI index over the 20th century. Irrigation decreased the simulated variability of both the MI index and the lower-level temperature contrasts, and it decreased the atmospheric moisture transport. When included, the GHG forcing amplified these decreases and further induced a declining trend in the variability of the driving temperature contrasts over the twentieth century. There were strong decreases to the Bowen ratio, which altered the surface energy balance, and transport of atmospheric water vapor. By including irrigation along with GHG forcing, simulated MI variability was made more consistent with the reanalysis products. These findings are consistent with previous studies that evaluate the regional impact of irrigation on the moisture transport and rainfall associated with the SASM. This study further highlighted some inconsistencies between the reanalysis products used, which should be considered when they are used for future regional assessments in South Asia.

Future work may focus on the relationships between altered surface energy balance, weakened low-level winds and regional moisture availability and transport. These will need to include the interactions with additional regional forcings, including those of "atmospheric brown clouds", rising SSTs, changes to winter snowfall and rising surface temperatures outside of heavily irrigated regions. Groundwater used for extensive irrigation is also not an infinite resource, and future study building upon this work should account for changes in (or reductions to) irrigation water availability over the course of the twentyfirst century. Such studies will be useful to helping assess predictability of regional and local surface energy balance.

Acknowledgments This research was supported by an appointment to the NASA Postdoctoral Program at the Goddard Institute for Space Studies, administered by Oak Ridge Associated Universities through a contract with NASA. M. J. Puma gratefully acknowledges funding for Interdisciplinary Global Change Research under NASA cooperative agreement NNX08AJ75A supported by the NASA Climate and Earth Observing Program. The authors thank two anonymous reviewers whose comments greatly improved the quality of this manuscript. Resources supporting this work were provided by the NASA High-End Computing (HEC) Program through [the NASA Advanced Supercomputing (NAS) Division at Ames Research Center and] the NASA Center for Climate Simulation (NCCS) at Goddard Space Flight Center. 


\section{References}

Alory G, Meyers G (2009) Warming of the Upper Equatorial Indian Ocean and changes in the heat budget (1960-99). J Clim 24:93-113

Ball JT, Woodrow IE, Berry JA (1987) A model predicting stomatal conductance and its application to the control of photosynthesis under different environmental conditions. In: Biggins I (ed) Progress in photosynthesis. Nijhoff, Zoetermeer, pp 221-224

Bonfils C, Lobell D (2007) Empirical evidence for a recent slowdown in irrigation-induced cooling. Proc Natl Acad Sci 104(34):13,582

Compo GP, Whitaker JS, Sardeshmukh PD, Matsui N, Allan RJ, Yin $\mathrm{X}$, Gleason BE, Vose RS, Rutledge G, Bessemoulin P, Brönnimann S, Brunet M, Crouthamel RI, Grant AN, Groisman PY, Jones PD, Kruk M, Kruger AC, Marshall GJ, Maugeri M, Mok HY, Nordli O, Ross TF, Trigo RM, Wang XL, Woodruff SD, Worley SJ (2011) The twentieth century reanalysis project. Q J R Meteorol Soc 137:1-28

Cook BI, Puma MJ, Krakauer NY (2011) Irrigation induced surface cooling in the context of modern and increased greenhouse gas forcing. Clim Dyn 37:1587-1600

Cramer W (2006) Air pollution and climate change both reduce Indian rice harvests. Proc Natl Acad Sci 103(52):19609-19610

Douglas EM, Niyogi D, Frolking S, Yeluripati JB, Pielke RA Sr, Niyogi N, Vorosmarty CJ, Mohanty UC (2006) Changes in moisture and energy fluxes due to agricultural land use and irrigation in the Indian Monsoon Belt. Geophys Res Lett 33:L14403. doi:10.1029/2006GL026550

Douglas EM, Beltran-Przekurat A, Niyogi D, Pielke RA Sr, Vorosmarty CJ (2009) The impact of agricultural intensification and irrigation on land-atmosphere interactions and Indian monsoon precipitation-a mesoscale modeling perspective. Global Planet Change 67:117-128

Farquhar GD, von Caemmerer S, Berry JA (1980) A biochemical model of photosynthetic $\mathrm{CO}_{2}$ assimilation in leaves of $\mathrm{C} 3$ species. Planta 149:78-90

Federer CA, Vörösmarty C, Fekete B (2003) Sensitivity of annual evaporation to soil and root properties in two models of contrasting complexity. J Hydrometeorol 4(6):1276-1290

Freydank, K, Siebert S (2008) Towards mapping the extent of irrigation in the last century: time series of irrigated area per country. Tech. Rep. Frankfurt Hydrol. Pap. 08, Inst. of Phys. Geogr., Univ. of Frankfurt, Frankfurt, Germany

Guimberteau M, Laval K, Perrier A, Polcher J (2011) Global effect of irrigation and its impact on the onset of the Indian summer monsoon. Clim Dyn. doi:10.1007/s00382-011-1251-5

Hansen J, Sato M, Ruedy R, Kharecha P, Lacis A, Miller R, Nazarenko L, Lo K, Schmidt GA, Russell G, Aleinov I, Baue S, Baum E, Cairns B, Canuto V, Chandler M, Cheng Y, Cohen A, Del Genio A, Faluvegi G, Fleming E, Friend A, Hall T, Jackman C, Jonas J, Kelley M, Kiang NY, Koch D, Labow G, Lerner J, Menon S, Novakov T, Oinas V, Perlwitz J, Perlwitz J, Rind D, Romanou A, Schmunk R, Shindell D, Stone P, Sun S, Streets D, Tausnev N, Thresher D, Unger N, Yao M, Zhang S (2007) Climate simulations for 1880-2003 with GISS modelE. Clim Dyn 29:661-696. doi:10.1007/s00382-007-255-8

Hazel PBR (2009) The Asian Green Revolution. IFPRI Discussion Paper 00911

Jha S (2001) Rainwater Harvesting in India. Press Information Bureau, Government of India, New Delhi, India. http://pib.nic. in/feature/feyr2001/fsep2001/f060920011.html. Accessed 12 June 2006

Kalnay E, Kanamitsu M, Kistler R, Collins W, Deaven D, Gandin L, Iredell M, Saha S, White G, Woollen J, Zhu Y, Chelliah M, Ebisuzaki W, Higgins W, Janowiak J, Mo KC, Ropelewski C, Wang J, Leetmaa A, Reynolds R, Jenne R, Joseph D (1996) The
NCEP/NCAR 40-year reanalysis project. Bull American Met Soc 77(3):437-471

Krishna Kumar K, Rupa Kumar K, Ashrit RG, Deshpande NR, Hansen JW (2004) Climate impacts on Indian agriculture. Int J Climatol 24:1375-1393

Kueppers L, Snyder M, Sloan L (2007) Irrigation cooling effect: regional climate forcing by land-use change. Geophys Res Lett 34(3):L03,703

Lal M (2011) Implications of climate change in sustained agricultural productivity in South Asia. Reg Environ Change Suppl 1:S79S94

Lau KM, Kim MK, Kim KM (2006) Asian summer monsoon anomalies induced by aerosol direct forcing: the role of the Tibetan Plateau. Clim Dyn 26:855-864

Lee E, Chase TN, Rajagopalan B, Barry RG, Biggs TW, Lawrence PJ (2008) Effects of irrigation and vegetation activity on early Indian summer monsoon variability. Intl $\mathrm{J}$ Climatol. doi: 10.1002/joc. 1721

Lobell D, Bonfils C, Faures J (2008) The role of irrigation expansion in past and future temperature trends. Earth Interact 12(3):1-11

Mall RK, Gupta A, Singh R, Sing RS, Rathore LS (2006a) Water resources and climate change: an Indian perspective. Curr Sci 90:1610-1626

Mall RK, Singh R, Gupta A, Srinivasan G, Rathore LS (2006b) Impact of climate change on Indian agriculture: a review. Clim Change 78:445-478

Matthews E (1983) Global vegetation and land use: new highresolution data bases for climate studies. J Appl Meteorol 22(3):474-487

Matthews E (1984) Prescription of land surface boundary conditions in GISS GCM II: a simple method based on fine resolution data bases, NASA Tech Memo, 86096, p 20

Niyogi D, Kishtawal C, Tripathi S, Govindaraju RS (2010) Observational evidence that agricultural intensification and land use change may be reducing the Indian summer monsoon rainfall. Water Resour Res 46:W03533. doi:10/1029/2008WR007082

Parthasarathy B, Munot AA, Kothawale DR (1995) All India monthly and seasonal rainfall series: 1871-1993. Theor Appl Climatol 49:217-224

Puma MK, Cook BI (2010) Effects of irrigation on global climate during the 20th century. J Geophys Res 115:D16,120

Ramanathan V, Agrawal M, Akimoto H, Auffhammer M, Devotta S, Emberson L, Hasnain SI, Iyngararasan M, Jayaraman A, Lawrence M, Nakajima T, Oki T, Rodhe H, Ruchirawat M, Tan SK, Vincent J, Wang JY, Yang D, Zhang YH, Autrup H, Barregard L, Bonasoni P, Brauer M, Brunekreef B, Carmichael G, Chung CE, Dahe J, Feng Y, Fuzzi S, Gordon T, Gosain AK, Htun N, Kim J, Mourato S, Naeher L, Navasumrit P, Ostro B, Panwar T, Rahman MR, Ramana MV, Rupakheti M, Settachan D, Singh AK, St. Helen G, Tan PV, Viet PH, Yinlong J, Yoon SC, Chang WC, Wang X, Zelikoff J, Zhu A (2008) Atmospheric Brown Clouds: Regional Assessment Report with Focus on Asia, published by the United Nations Environment Program, Nairobi, Kenya, pp 1-360

Saeed F, Hagemann S, Jacob D (2009) Impact of irrigation on the South Asian summer monsoon. Geophys Res Lett 36:L20711. doi:10.1029/2009GL040625

Schmidt GA, Ruedy R, Hansen JE, Aleinov I, Bell N et al (2006) Present-day atmospheric simulations using GISS ModelE: comparison to in situ, satellite and reanalysis data. J Clim 19:153-191

Sen Roy S, Mahmood R, Niyogi D, Lei M, Foster SA, Hubbard KG, Douglas E, Pielke Sr. R (2007) Impacts of the agricultural Green Revolution-induced land use changes on air temperatures in India. J Geophys Res 112:D21,108 
Sen Roy S, Mahmood R, Quintanar AI, Gonzalez A (2010) Impacts of irrigation on dry season precipitation in India. Theor Appl Climatol. doi:10/1007/s00704-010-0338-z

Shukla S (2011) The Impact of a Warmer Climate on Atmospheric Circulation with Implications for the Asian Summer Monsoon. Doctoral Dissertation, Columbia University

Siebert S, Döll P, Feick S, and Hoogeveen J (2005a) Global map of irrigated areas version 2.2. Tech. Rep., Johann Wolfgang Goethe Univ., Frankfurt, Germany

Siebert S, Döll P, Hoogeveen J, Faures JM, Frenken K, Feick S (2005b) Development and validation of the global map of irrigation areas. Hydrol Earth Syst Sci 9(5):353-547
Sun Y, Ding Y, Dai A (2010) Changing links between Summer Asian summer monsoon circulation and tropospheric land-sea thermal contrasts under a warming scenario. Geophys Res Lett 37:L02,704

Wang B (2006) The Asian monsoon. Springer, Chichester

Webster PJ, Yang S (1992) Monsoon and ENSO: selectively interactive systems. Q J R Meteorol Soc 118:877-926

Wisser D, Fekete BM, Vorosmarty CJ, Schumann AH (2010) Reconstructing 20th century global hydrography: a contribution to the global terrestrial network-hydrology (GTN-H). Hydrol Earth Syst Sci 14:1-24

Yanai M, Wu GX (2006) Effects of the Tibetan Plateau. In: Wang B (ed) The Asian monsoon. Sringer, Chichester, pp 513-549 